\title{
Evaluation of Craniofacial Morphology of Children with Dental Fluorosis in Early Permanent Dentition Period
}

\author{
Alev Aksoy Dogana \\ Pinar Bolpacab
}

\section{ABSTRACT}

Objectives: High intake of fluoride (>1.5 mg/L) for a prolonged period may lead to skeletal fluorosis as well as dental fluorosis. The aim of this study was to compare the craniofacial characteristics of children with dental fluorosis in early permanent dentition period to those without fluorosis.

Methods: Two hundred and sixteen children in early permanent dentition (girls:121, boys:95) were included in the study. Study group was composed of 124 children with dental fluorosis who was born and grew up in Isparta (girls:75, boys:49) whereas control group of children (n=92: 46 girls and 46 boys) had no dental fluorosis. Dental fluorosis was classified using Thylstrup Fejerskov Fluorosis Index. Radiological evaluation was performed by cephalometric tracing using Björk analysis. Statistical evaluation in between study and control groups was done by Independent Samples T test and comparison with Björk's standards was done by One Sample T test analysis. The association between two quantitative variables was evaluated with Pearson's correlation coefficient (rho).

Results: The mean dental fluorosis level was $4.6 \pm 1.8$ for children with fluorosis. Systemic fluorosis affect girls no different than boys in the early permanent dentition period because none of the angular measurements show significant difference between boys and girls in the fluoridated group. Comparison of craniofacial angular values of boys with fluorosis show greater diversity compared to boys without fluorosis against Björk's mean values for boys.

Conclusions: Craniofacial morphology of children with fluorosis did not show great diversity than the ones without fluorosis in the early permanent dentition period. None of the angular measurements were significantly different between boys and girls in the fluoridated group which might imply that systemic fluorosis did not show gender difference in the early permanent dentition. (Eur J Dent $2009 ; 3: 304-3131$

Key words: Craniofacial morphology; Fluorosis; Cephalometrics; Björk analysis.

a Assistant Professor, Department of Orthodontics, Faculty of Dentistry, Suleyman Demirel University, Isparta, Turkey.

b Research Assistant, Department of Prosthodontics, Faculty of Dentistry, Erciyes University, Kayseri, Turkey.

Corresponding author: Dr. Alev Aksoy Dogan Suleyman Demirel University, Faculty of Dentistry Department of Orthodontics,32100 Isparta, Turkey. Phone :+90 2462113374

Fax : :902462370607

E-mail :alevak2000ahotmail.com

\section{INTRODUCTION}

Skeletal and dental fluorosis is an endemic public health problem in some regions of various countries around the world. ${ }^{1-3}$ Fluoride is mainly incorporated into calcified tissues (i.e., bones and teeth) because of its high affinity for calcium. It replaces the hydroxyl group of hydroxyapatit crystals to form fluorapatit which is less soluble and more compact. It increases metabolic turnover of the bone and stimulates bone cell proliferation. High intake of fluoride (>1.5 mg/L) for a prolonged 
period is known to cause dental and skeletal fluorosis while $1 \mathrm{ppm}$ (parts per million) of sodium fluoride were reported to be safe level in drinking water. ${ }^{4}$

During research in the heavily fluoride-polluted area of the Ore mountains and their southern foreland, a high prevalence of pathological bone changes was also found in the mandibles of fluorotic red deer. ${ }^{5,6} \mathrm{Xu}$ et al ${ }^{7}$ reported articular calcification and necrosis of articular chondrocytes in skeletal fluorosis. Czarnowsky et $a{ }^{8}$ showed that increased fluoride intake affects the fluoride levels in urine and hair and also has an impact on bone density. In mice exposed to a wide range of fluor in their diet, tooth fluoride concentration, confirms the use of tooth as a biomarker of skeletal exposure. ${ }^{9}$

In Turkey, the city of Isparta, located in the south Mediterranean region of Turkey, is one of the severe endemic fluorosis regions. Natural water supply is the major source of fluoride ions. The amount of fluoride in drinking water at some regions of the city is determined as high as 1.8$3.8 \mathrm{mg} / \mathrm{l}$ with a mean level of $2.7 \mathrm{ppm}$. Because of high fluoride intake, severe dental fluorosis is commonly encountered. ${ }^{3}$ Skeletal and joint deformities were also reported in the city. ${ }^{2}$

Orthodontic treatment in the early permanent dentition is a common treatment modality. Relative cephalometric normative standards for young individuals are essential in the diagnosis of and treatment planning for these age groups. The purpose of the study was to evaluate the craniofacial characteristics of children with fluorosis in the early permanent dentition period using Björk analysis $^{10}$ and to investigate certain differences connected with the high fluor intake. We compared Turkish children with and without fluorosis living in different environmental conditions in different regions to determine the craniofacial differences. We also compared our results with the standard values of Björk.

\section{MATERIALS AND METHODS}

Subjects

A total of 216 (girls:121, boys:95) children in the early permanent dentition were included in the present study. The study group was composed of 124 children (girls:75, boys:49) who referred to Clinics of Dental Faculty, Suleyman Demirel
University (in Isparta, endemic fluorosis region). Ninety two children (girls:46, boys:46) who applied to Okmeydani Dental Hospital (in Istanbul, non-endemic fluorosis region) was selected as the control group. Patients with any metabolic bone disease or inflammatory disease were excluded from the study. Patients who had undergone orthodontic treatment or with parafunctional habits were also excluded from the study (Table 1).

The clinical diagnosis and classification of dental fluorosis was established using the Thylstrup Fejerskov Fluorosis Index. ${ }^{11}$ Representative photographs showing different levels of dental fluorosis were presented in Figure 1.

\section{Cephalometric analysis}

The cephalometric radiographs were taken with the subjects standing with their teeth occluded and the lips in a relaxed position. The films were traced on acetate paper. Björk analysis ${ }^{10}$ were used for the evaluation of cephalograms to determine cranio-facial morphology. Björk analysis established for the Swedish children was used to serve the standart values. Angular (Figure 2) and linear (Figure 3) measurements were performed to determine the facial characteristics of the children with and without fluorosis.

\section{Statistical analysis}

Data were analyzed using the SPSS (version 11) for Windows (SPSS; Chicago, Illinois, USA) statistical package. The results were expressed as the minimum, maximum, mean and standard deviation for quantitative variables and as frequencies for categorical findings. Independent Samples T test analysis was used to compare the angular and linear measurements of children with and without fluorosis. The difference between angular measurements on male population in Björk study and in our study group was done by using One Sample $\mathrm{T}$ test. The association between two quantitative variables was evaluated with Pearson's correlation coefficient (rho). Significance levels were set at 0.05 .

\section{Reliability}

A replicate measurement trial was performed on 10 randomly selected cephalograms of children in the early permanent dentition period. A second set of tracings was carried out after an interval of 
at least two weeks. In order to estimate the measurement error, Dahlberg's formula $\mathrm{Se}=V\left(\left[\mathrm{~d}^{2 / 2} n\right)\right.$ was used, where $d$ is the difference between repeated measurements and $n$ is the number of paired measurement. ${ }^{12}$

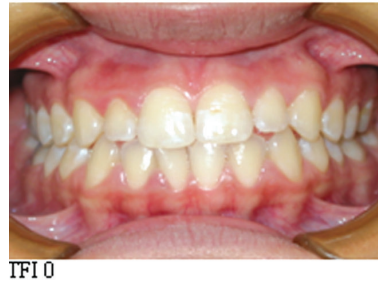

TFI 0

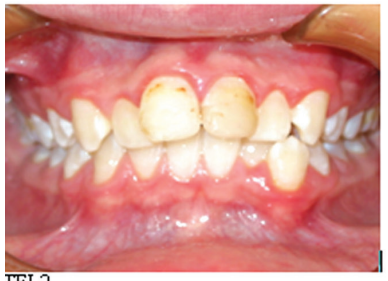

TFI 2
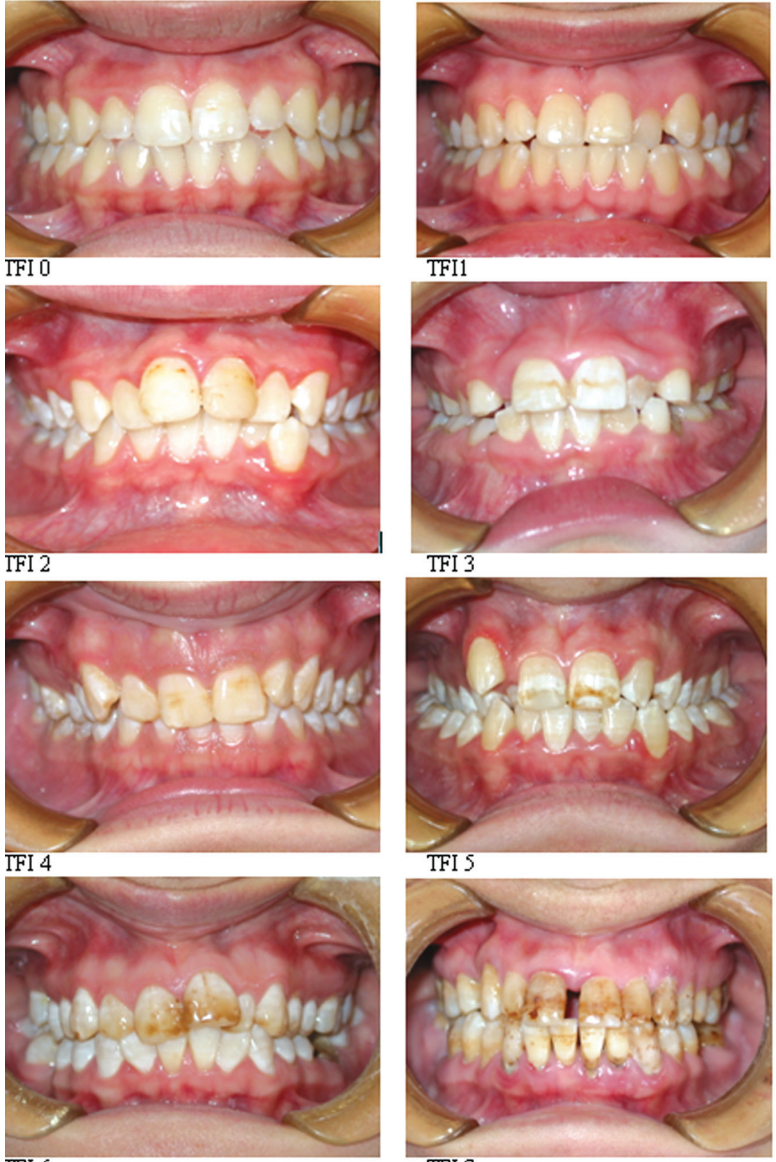

TFI 6
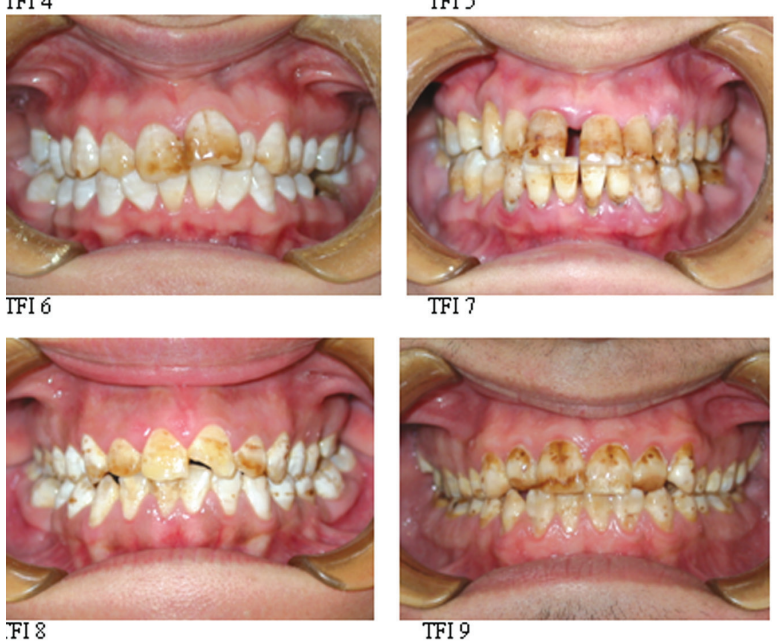

TFI ?

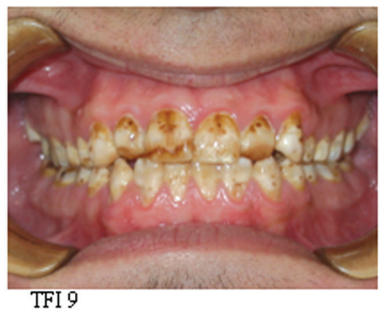

Figure 1. Thylstrup and Fejerskov Fluorosis Index (TFI) samples.

\section{RESULTS}

In general, measurement errors were small; no variable reached the 5 per cent level of significance in the paired t-test. The mean age of the children included in the study was $13.8 \pm 1.2$ $114.4 \pm 0.9$ for children with fluorosis; $12.9 \pm 1.2$ for children without fluorosis). The distributions of individuals in each group were shown in Table 1.

The mean dental fluorosis level was found $4.6 \pm 1.8$ (minimum 2; maximum 9) according to Thylstrup Fejerskov Fluorosis Index for children with fluorosis.

Values of cephalometric measurements of children with and without fluorosis are given in Tables 2-5. Table 2 shows the differences of angular and linear measurements of the two groups according to gender. Differences of craniofacial morphology of individuals with and without fluorosis were shown in Table 3 and separately for girls and boys, in Tables 4 and 5 . The results showed that angular or linear measurements were not statistically significant between children with and without fluorosis. The only exception was the angle of convexity (NAPog) which was significantly higher in children without fluorosis than children with fluorosis (Tables 3-5).

For all angular measurements, the differences between the genders were not statistically significant for children with and without fluorosis except Saddle (NSAr) and Gonial angle (ArGoGn) (P<.05). Linear variables, such as anterior cranial base $(S N)(P<.05)$, posterior cranial base (SAr) $(P<.01)$, anterior facial height $(\mathrm{NMe})(\mathrm{P}<.01)$, lower facial height $(\mathrm{MePMe})(\mathrm{P}<.01)$ were consistently larger in boys than in girls at both groups having and not having dental fluorosis (Table 2).

Girls showed statistically significant difference in NSAr $(P<.05), N A P o g(P<.05)$, and ramus height (Arkk) $(P<.01)$ in between two groups (Table 4) whereas articular angle (SArGo) $(P<.001)$, ArGoGn $(P<.05)$, chin angle $(I d P o g-M G o)(P<.001)$ and NA-

Table 1. Fluorosis, gender cross tabulation.

\begin{tabular}{lccccccc}
\hline & \multicolumn{7}{c}{ Gender } \\
\cline { 2 - 8 } & \multicolumn{3}{c}{ Girls } & \multicolumn{1}{c}{ Boys } & \multicolumn{2}{c}{ Total } \\
\cline { 2 - 8 } & $\mathrm{N}$ & $\%$ & $\mathrm{~N}$ & $\%$ & $\mathrm{~N}$ & $\%$ \\
\hline Without flourosis & 46 & 21.3 & 46 & 21.3 & 92 & 42.6 \\
With flourosis & 75 & 34.7 & 49 & 22.7 & 124 & 57.4 \\
Total & 121 & 56 & 95 & 44 & 216 & 100 \\
\hline
\end{tabular}


Pog $(P<.01)$ (Table 5) showed significant difference in boys for different groups.

Comparison of craniofacial angular values of boys with and without fluorosis with Björk's mean values shows different significance for NSAr, SArGo, mandibular prognathism (SNId) and NAPog (Table 6).

Correlations of angles for children with fluorosis in the early permanent dentition period are shown in Table 7. NSAr shows negative correlation with SArGo, SNPr, SNId angles for boys and girls. For total children and girls SArGo shows negative correlation with ArGoGn and ArNPr. ArGoGn have negative correlation with only IdPog-MGo for all of the children. ArNPr is positively correlated with SNPr, SNId, IdPog-MGo whereas it is negatively correlated with NAPog. SNPr is also positively correlated with SNId and IdPog-MGo. IdPog-MGo shows negative correlation with NAPog for all of the children.

\section{DISCUSSION}

Endemic fluorosis is a chronic metabolic bone and joint disease caused by intake of large amounts of fluoride. Marked increase in bone for-

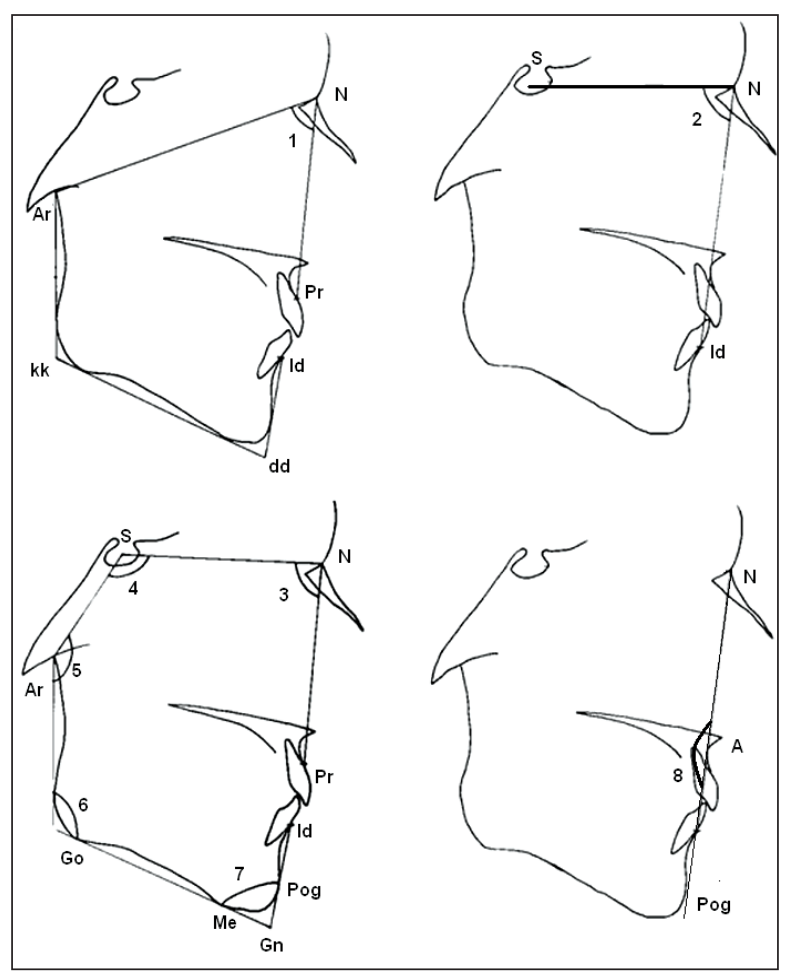

Figure 2. Björk Analysis Angular Measurements: (1) Angle of facial prognathism (ArNPr), (2) Angle of mandibular prognathism(SNId), (3) Angle of maxillary prognathism (SNPr), (4) Saddle angle (NSAr), (5) Articular angle (SArGo), (6) Gonial (Jaw) angle (ArGoGn), (7) Chin angle (IdPog-MGo) (8) Facial convexity (NAPog). mation, with irregular deposition of osteoid tissue, induced by fluoride results in osteosclerosis, exocytose formation and calcification of tendons and ligaments. ${ }^{2}$ Skeletal fluorosis may cause pain, deformities, and limited movement of the joints of the spinal skeleton and major joints of extremities. Savas et $\mathrm{al}^{2}$ observed that high number of female patients living in Isparta who had dental fluorosis also complained of knee pain. They found that radiological severity of knee osteoarthritis was greater and atypically located osteophytes were more frequent in patients with endemic fluorosis. They implied that endemic fluorosis might be responsible for the increased severity of degenerative changes in the bone.

Washington, DC: National Academy ${ }^{13}$ concluded that the severity of the disease appears to be directly related to the magnitude and duration of high-fluoride exposure. In an animal model, it was shown that tooth fluoride content was correlated with bone fluoride content where animals were exposed to a wide range of fluor in their drinking water. However, in the same study it was also shown that in humans and mice exposed to narrow ranges of fluoride ingestion, no correlation existed between tooth fluor concentration and bone fluoride concentration. A strong positive correlation between the degree of dental fluorosis and mandibular bone fluoride content was found in a sample of red deer exposed to elevated levels of fluoride, thus demonstrating the usefulness of dental fluorosis as a biomarker of increased fluoride exposure for biomonitoring studies. ${ }^{14}$ As for shown in clinical and experimental animal studies, prolonged uptake of increased amounts of

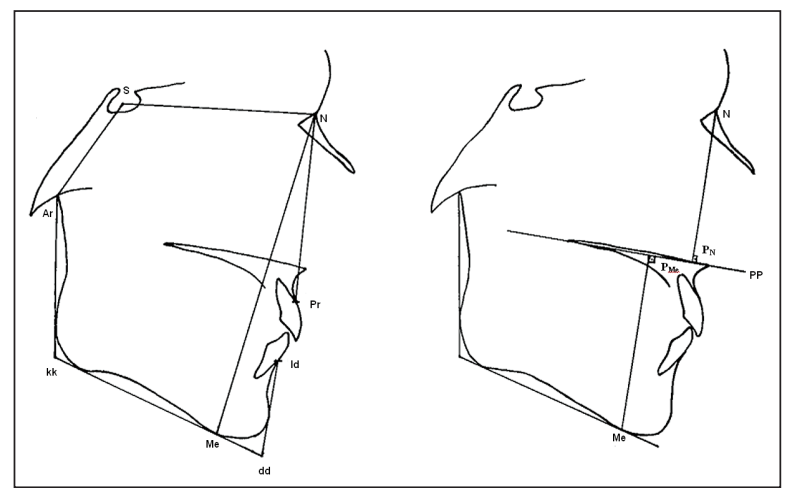

Figure 3. Björk Analysis Linear Measurements: Anterior Cranial Base (SN), Posterior Cranial Base (SAr), Ramus Mandibularis Length (Arkk), Corpus Mandibularis Length (kkdd), Mandibulo-alveolar height (Iddd), Anterior Facial Height (NMe), Upper Facial Height $\left(\mathrm{NP}_{\mathrm{N}}\right)$, Lower Facial Height $\left(\mathrm{MeP}_{\mathrm{Me}}\right)$. 
fluoride leads to osteomalacia and decreased biomechanical competence of bone. ${ }^{15-19}$ Miyagi et al ${ }^{20}$ examined the effect of fluoride intake on the mineral content in rat alveolar bone. They concluded that fluoride intake might have a protective effect on rapidly progressing alveolar bone resorption.
However, laboratory studies have demonstrated that fluoride does not readily diffuse into alreadyformed bone but is incorporated as bone remodels or develops in children. ${ }^{21}$ Therefore, dental fluorosis was used as a biomarker to evaluate the effects of high fluoride intake on bony components

Table 2. Gender difference of the craniofacial morphology of Turkish children with and without fluorosis.

\begin{tabular}{|c|c|c|c|c|c|c|c|c|c|}
\hline & & & & Girls & & & Boys & & \\
\hline & & Measurements & $\mathrm{N}$ & Mean & SD & $\mathrm{N}$ & Mean & SD & $P^{1}$ \\
\hline \multirow{16}{*}{ 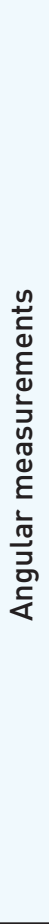 } & \multirow{8}{*}{ 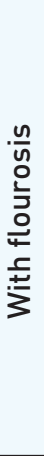 } & NSAr & 75 & 124.8 & 5.8 & 49 & 123.1 & 5.3 & .109 \\
\hline & & SArGo & 75 & 143.9 & 6.3 & 49 & 145.8 & 5.3 & .077 \\
\hline & & ArGoGn & 75 & 128 & 6.3 & 49 & 129.7 & 5.5 & .133 \\
\hline & & ArNPr & 75 & 64.4 & 4.1 & 49 & 63.5 & 3.6 & .200 \\
\hline & & SNPr & 75 & 82.9 & 4.5 & 49 & 82.3 & 4.1 & .664 \\
\hline & & SNId & 75 & 78.7 & 4.5 & 49 & 78.9 & 4.2 & .791 \\
\hline & & IdPog-MGo & 75 & 70.6 & 7.1 & 49 & 70.9 & 6.1 & .797 \\
\hline & & NAPog & 75 & 176 & 7.4 & 49 & 175.3 & 7.8 & .608 \\
\hline & \multirow{8}{*}{ 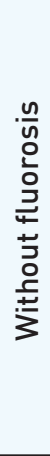 } & NSAr & 46 & 127.1 & 5.6 & 46 & 124.7 & 5.1 & $.041^{*}$ \\
\hline & & SArGo & 46 & 141.8 & 6.6 & 46 & 138.9 & 20.2 & .366 \\
\hline & & ArGoGn & 46 & 129.4 & 6.4 & 46 & 132.3 & 6.9 & $.038 *$ \\
\hline & & ArNPr & 46 & 64.5 & 2.9 & 46 & 63.4 & 3 & .087 \\
\hline & & SNPr & 46 & 83 & 6.2 & 46 & 81.2 & 4 & .090 \\
\hline & & SNId & 46 & 77.4 & 6.4 & 46 & 77.6 & 3.5 & .801 \\
\hline & & IdPog-MGo & 46 & 68.8 & 5.8 & 46 & 66.8 & 4.9 & .076 \\
\hline & & NAPog & 46 & 178.8 & 6 & 46 & 179.7 & 6.4 & .499 \\
\hline \multirow{16}{*}{ 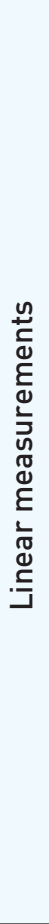 } & \multirow{8}{*}{ 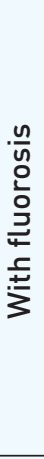 } & SN & 75 & 70.3 & 3.7 & 49 & 71.8 & 3.9 & $.032^{*}$ \\
\hline & & SAr & 75 & 35.1 & 4.1 & 49 & 37.2 & 3 & $.002^{* *}$ \\
\hline & & Arkk & 75 & 47.2 & 4.5 & 49 & 47.6 & 4.1 & .551 \\
\hline & & Kkdd & 75 & 78.8 & 5.6 & 49 & 80.7 & 5.7 & .068 \\
\hline & & Iddd & 75 & 35.1 & 4.2 & 49 & 36 & 4.5 & .287 \\
\hline & & $\mathrm{NMe}$ & 75 & 119.7 & 6.9 & 49 & 124.5 & 8.4 & $.001^{* *}$ \\
\hline & & $N P_{N}$ & 75 & 53.9 & 4.6 & 49 & 54.4 & 4.4 & .548 \\
\hline & & $\mathrm{MeP}_{\mathrm{Me}}$ & 75 & 63 & 4.8 & 49 & 66.2 & 5.3 & $.001^{* *}$ \\
\hline & \multirow{8}{*}{ 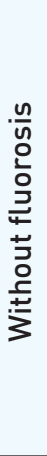 } & SN & 46 & 69.2 & 4.7 & 46 & 73.7 & 3.5 & $.032^{*}$ \\
\hline & & SAr & 46 & 34.9 & 3 & 46 & 36.6 & 3.5 & $.002^{* *}$ \\
\hline & & Arkk & 46 & 44.6 & 4.5 & 46 & 47.1 & 5 & .551 \\
\hline & & Kkdd & 46 & 79.8 & 5.2 & 46 & 82.4 & 5.8 & .068 \\
\hline & & Iddd & 46 & 34.8 & 3.4 & 46 & 35.6 & 3 & .287 \\
\hline & & $\mathrm{NMe}$ & 46 & 119.3 & 6.7 & 46 & 124.9 & 7.4 & $.001^{* *}$ \\
\hline & & $N P_{N}$ & 46 & 52.8 & 4 & 46 & 55.3 & 3 & .548 \\
\hline & & $\mathrm{MeP}_{\mathrm{Me}}$ & 46 & 64 & 4.7 & 46 & 66.8 & 4.3 & $.001^{* *}$ \\
\hline
\end{tabular}

*: $P<.05 ; * *: P<.01$ 
of face. For this reason, our experimental group was selected from children living in endemic fluorosis region; Isparta, since birth.

In this study, craniofacial morphology of children with severe dental fluorosis in the early permanent dentition period were investigated. Boys consistently showed larger values for all of the linear variables, but the angular variables were usually not found to be different between the sexes (Table 2). This finding is in agreement with other studies dealing with children of the same age..22-23 In children with fluorosis, ArNPr and SNId shows negative correlation with NSAr which are frequently used in cephalometric tracings. ${ }^{24}$ Maxilla and mandible indicated anterior displacement when NSAr decreases in children with fluorosis, which shows parallelism with Björk's standarts. ${ }^{10}$ None of the angular values showed statistical difference between boys and girls in the fluoridated group at the early permanent dentition period which might imply that systemic fluorosis had similar effect in both gender in the early permanent dentition period (Table 2). Facial and maxillary prognatism were slightly higher in the girls than in the boys both for children with and without fluorosis but the differences were not statistically significant which is comparable to the results reported by Johannsdottir et al. ${ }^{23}$ Regarding the linear measurements, the significantly larger SN, SAr, NMe and MePMe in boys $(P=.001)$ both with and without fluorosis shows parallelism with the study of Johannsdottir et a ${ }^{23}$ (Table 2).

Negative correlation of SArGo for children with fluorosis with ArNPr, IdPog-MGo showed parallelism with Björk analysis. In our study in which a possible reduction of the angle between the rear portion, or vertical part, of the cranial base and the ramus (SArGo), would be accompanied by an equal increase in the degree of prognathism, as the ramus and the profile are nearly parallel. A diminution of the SArGo would have the secondary effect of shortening the frontal facial height, thus diminishing the change in the angle of prognathism. ${ }^{25}$

According to Björk, a possible reduction in ArGoGn had little effect on the degree of prognathism. Negative correlation was found between ArGoGn and IdPog-MGo. A change in IdPog-MGo, the angle between the lower horizontal and anteri-

Table 3. Comparison of craniofacial morphology of both genders with and without fluorosis.

\begin{tabular}{|c|c|c|c|c|c|c|c|c|c|c|c|c|c|c|}
\hline \multirow{3}{*}{$\begin{array}{l}\text { Measurements } \\
\text { NSAr }\end{array}$} & \multicolumn{5}{|c|}{ With flourosis (Isparta) } & \multicolumn{5}{|c|}{ Without flourosis } & \multirow[b]{2}{*}{$P^{1}$} & \multirow[b]{2}{*}{ MD } & & \\
\hline & $N$ & Min & Max & Mean & SD & $\mathrm{N}$ & Min & Max & Mean & SD & & & \multicolumn{2}{|c|}{$95 \% \mathrm{Cl}$} \\
\hline & 124 & 110 & 138 & 124.1 & 5.6 & 92 & 112 & 137.5 & 125.9 & 5.4 & $.021 *$ & -1.8 & -3.3 & -0.3 \\
\hline SArGo & 124 & 125 & 156 & 144.6 & 6 & 92 & 13 & 160 & 141.6 & 6.9 & $.001 * *$ & 3 & 1.3 & 4.7 \\
\hline ArGoGn & 124 & 112 & 141 & 128.6 & 6 & 92 & 119 & 145 & 130.8 & 6.8 & $.014^{*}$ & -2.2 & -3.9 & -0.5 \\
\hline ArNPr & 124 & 48.5 & 74.5 & 64 & 3.9 & 92 & 57.5 & 71 & 64 & 3 & .928 & 0.04 & -0.9 & 1 \\
\hline SNPr & 124 & 71.5 & 94.5 & 82.07 & 4.3 & 92 & 73.5 & 101 & 82.1 & 5.3 & .967 & -0.03 & -1.3 & 1.3 \\
\hline SNId & 124 & 69 & 91 & 78.7 & 4.4 & 92 & 60 & 90 & 77.5 & 5.1 & .058 & 1.2 & 0 & 2.5 \\
\hline IdPog-MGo & 124 & 57 & 87 & 70.7 & 6.7 & 92 & 56 & 83 & 67.8 & 5.4 & $.001^{* *}$ & 2.9 & 1.2 & 4.6 \\
\hline NAPog & 124 & 159 & 194.5 & 175.7 & 7.5 & 92 & 161 & 191 & 179.3 & 6.2 & $.000^{* * *}$ & -3.6 & -5.5 & -1.7 \\
\hline SN & 124 & 59 & 83 & 70.9 & 3.8 & 92 & 61 & 82 & 71.4 & 4.7 & .361 & -0.5 & -1.7 & 0.6 \\
\hline SAr & 124 & 23 & 47 & 36 & 3.9 & 92 & 27.5 & 45 & 35.8 & 3.4 & .677 & 0.2 & -0.8 & 1.2 \\
\hline Arkk & 124 & 35 & 63 & 47.3 & 4.4 & 92 & 36.5 & 60 & 45.8 & 4.9 & $.018^{*}$ & 1.5 & 0.3 & 2.7 \\
\hline Kkdd & 124 & 66 & 95 & 79.5 & 5.7 & 92 & 71.5 & 93.5 & 81.1 & 5.7 & $.045^{*}$ & -1.6 & -3.1 & -0.1 \\
\hline Iddd & 124 & 21.5 & 47 & 35.44 & 4.3 & 92 & 29 & 46 & 35.2 & 3.2 & .632 & -0.5 & -2.6 & 1.6 \\
\hline $\mathrm{NMe}$ & 124 & 104 & 140 & 121.6 & 7.9 & 92 & 110 & 143 & 122.1 & 7.5 & .975 & 0.02 & -1.1 & 1.2 \\
\hline $\mathrm{NP}_{\mathrm{N}}$ & 124 & 44 & 69 & 54.1 & 4.5 & 92 & 45 & 61 & 54.1 & 3.8 & .108 & -1.1 & -2.5 & 0.2 \\
\hline $\mathrm{MeP}_{\mathrm{Me}}$ & 124 & 52 & 75 & 64.3 & 5.2 & 92 & 56 & 76 & 65.4 & 4.7 & .63 & 0.3 & -0.8 & 1.3 \\
\hline
\end{tabular}

${ }^{1}$ Independent samples $\mathrm{T}$ test $\mathrm{SD}=\mathrm{Standard}$ deviation $\mathrm{MD}=$ Mean difference $\mathrm{Cl}=$ Confidence Interval of the difference ${ }^{* * *}: P<.001 ;{ }^{* *}: P<.01 ; *: P<.05$. 
Table 4. Comparison of craniofacial morphology of girls with and without fluorosis.

\begin{tabular}{|c|c|c|c|c|c|c|c|c|c|c|c|c|c|c|}
\hline \multirow{3}{*}{$\begin{array}{l}\text { Measurements } \\
\text { NSAr }\end{array}$} & \multicolumn{5}{|c|}{ With flourosis (Isparta) } & \multicolumn{5}{|c|}{ Without flourosis } & \multirow[b]{2}{*}{$P^{1}$} & \multirow[b]{2}{*}{ MD } & & \\
\hline & $\mathrm{N}$ & Min & Max & Mean & SD & $\mathrm{N}$ & Min & Max & Mean & SD & & & \multicolumn{2}{|c|}{$95 \% \mathrm{Cl}$} \\
\hline & 75 & 110 & 138 & 124.8 & 5.8 & 46 & 112 & 137.5 & 127.1 & 5.6 & $.037^{*}$ & -2.3 & -4.4 & -0.1 \\
\hline SArGo & 75 & 125 & 156 & 143.9 & 6.3 & 46 & 130.5 & 152 & 141.8 & 6.6 & .086 & 2.1 & -0.3 & 4.5 \\
\hline ArGoGn & 75 & 112 & 141 & 128 & 6.3 & 46 & 119 & 143.5 & 129.4 & 6.4 & .251 & -1.4 & -3.7 & 1 \\
\hline $\mathrm{ArNPr}$ & 75 & 48.5 & 74.5 & 64.4 & 4.1 & 46 & 58 & 69 & 64.5 & 2.9 & .85 & -0.1 & -1.5 & 1.2 \\
\hline SNPr & 75 & 71.5 & 94.5 & 81.9 & 4.5 & 46 & 73.5 & 101 & 83 & 6.2 & .263 & -1.1 & -3 & 0.8 \\
\hline SNId & 75 & 69 & 91 & 78.7 & 4.5 & 46 & 60 & 90 & 77.4 & 6.4 & .199 & 1.3 & -0.7 & 3.3 \\
\hline IdPog-MGo & 75 & 57 & 87 & 70.6 & 7.1 & 46 & 58.5 & 83 & 68.8 & 5.8 & .155 & 1.8 & -0.7 & 4.2 \\
\hline NAPog & 75 & 159 & 194.5 & 176 & 7.4 & 46 & 170 & 191 & 178.8 & 6 & $.029 *$ & -2.9 & -5.4 & -0.3 \\
\hline SN & 75 & 63 & 79 & 70.3 & 3.7 & 46 & 61 & 80 & 69.2 & 4.7 & .152 & 1.1 & -0.4 & 2.6 \\
\hline SAr & 75 & 23 & 47 & 35.1 & 4.1 & 46 & 27.5 & 41.5 & 34.9 & 3 & .781 & 0.2 & -1.2 & 1.6 \\
\hline Arkk & 75 & 35 & 63 & 47.2 & 4.5 & 46 & 36.5 & 55 & 44.6 & 4.5 & $.003^{* *}$ & 2.5 & 0.9 & 4.2 \\
\hline Kkdd & 75 & 66 & 91 & 78.8 & 5.6 & 46 & 71.5 & 90 & 79.8 & 5.2 & .33 & -1 & -3 & 1 \\
\hline Iddd & 75 & 21.5 & 47 & 35.1 & 4.2 & 46 & 29 & 46 & 34.8 & 3.4 & .663 & 0.3 & -1.1 & 1.8 \\
\hline $\mathrm{NMe}$ & 75 & 104 & 136 & 119.7 & 6.9 & 46 & 110 & 134.5 & 119.3 & 6.7 & .736 & 0.4 & -2.1 & 3 \\
\hline $\mathrm{NP}_{\mathrm{N}}$ & 75 & 44 & 69 & 53.9 & 4.6 & 46 & 45 & 61 & 52.8 & 4 & .201 & 1.1 & -0.6 & 2.7 \\
\hline $\mathrm{MeP}_{\mathrm{Me}}$ & 75 & 52 & 72 & 63 & 4.8 & 46 & 56 & 74 & 64 & 4.7 & .284 & -1 & -2.7 & 0.8 \\
\hline
\end{tabular}

${ }^{1}$ Independent samples $\mathrm{T}$ test. SD=Standard deviation, $\mathrm{MD}=$ Mean difference, $\mathrm{Cl}=$ Confidence Interval of the difference $^{* * *}: \mathrm{P}<.001 ;{ }^{* *}: \mathrm{P}<.01 ;{ }^{*}: \mathrm{P}<.05$.

Table 5. Comparison of craniofacial measurements of boys with and without fluorosis.

\begin{tabular}{|c|c|c|c|c|c|c|c|c|c|c|c|c|c|c|}
\hline \multirow{3}{*}{$\begin{array}{l}\text { Measurements } \\
\text { NSAr }\end{array}$} & \multicolumn{5}{|c|}{ With flourosis (Isparta) } & \multicolumn{5}{|c|}{ Without flourosis } & \multirow[b]{2}{*}{$P^{1}$} & \multirow[b]{2}{*}{ MD } & & \\
\hline & $\mathrm{N}$ & Min & Max & Mean & SD & $\mathrm{N}$ & Min & Max & Mean & SD & & & \multicolumn{2}{|c|}{$95 \% \mathrm{Cl}$} \\
\hline & 49 & 113 & 133 & 123.1 & 5.3 & 46 & 113 & 132 & 124.8 & 5.1 & .129 & -1.6 & -3.7 & 0.5 \\
\hline SArGo & 49 & 130 & 156 & 145.8 & 5.3 & 46 & 13 & 160 & 141.5 & 6.9 & $.001 * *$ & 4.3 & 0.9 & 6.9 \\
\hline ArGoGn & 49 & 118 & 140 & 129.7 & 5.5 & 46 & 122 & 145 & 132.3 & 6.9 & $.042^{*}$ & -2.6 & -5.2 & -0.1 \\
\hline ArNPr & 49 & 54 & 72.5 & 63.5 & 3.6 & 46 & 57.5 & 71 & 63.4 & 3 & .969 & 0.03 & -1.3 & 1.4 \\
\hline SNPr & 49 & 73 & 92 & 82.3 & 4.1 & 46 & 74.5 & 90 & 81.2 & 4 & .182 & 1.1 & -0.5 & 2.8 \\
\hline SNId & 49 & 71 & 86 & 78.9 & 4.2 & 46 & 72.5 & 89.5 & 77.6 & 3.5 & .125 & 1.2 & -0.3 & 2.8 \\
\hline IdPog-MGo & 49 & 60 & 87 & 70.9 & 6.1 & 46 & 56 & 80 & 66.8 & 4.9 & $.001 * *$ & 4.1 & 1.8 & 6.4 \\
\hline NAPog & 49 & 159.5 & 192 & 175.3 & 7.8 & 46 & 161 & 190 & 179.7 & 6.4 & $.003 * *$ & -4.4 & -7.4 & -1.5 \\
\hline SN & 49 & 59 & 83 & 71.8 & 3.9 & 46 & 69.5 & 82 & 73.7 & 3.5 & .17 & -1.9 & -3.4 & -0.3 \\
\hline SAr & 49 & 30 & 44 & 37.2 & 3 & 46 & 31 & 45 & 36.6 & 3.5 & .318 & 0.7 & -0.7 & 2 \\
\hline \multirow[t]{2}{*}{ Arkk } & 49 & 40 & 59 & 47.6 & 4.2 & 46 & 37.5 & 60 & 47.1 & 5 & .541 & 0.6 & -1.3 & 2.5 \\
\hline & 49 & 71 & 95 & 80.7 & 5.7 & 46 & 74 & 93.5 & 82.4 & 5.8 & .141 & -1.8 & -4.1 & 0.6 \\
\hline Iddd & 49 & 25 & 45 & 36 & 4.5 & 46 & 31 & 41 & 35.6 & 3 & .637 & 0.4 & -1.2 & 1.9 \\
\hline $\mathrm{NMe}$ & 49 & 110 & 140 & 124.5 & 8.4 & 46 & 112 & 143 & 124.9 & 7.4 & .786 & -0.4 & -3.7 & 2.8 \\
\hline NPN & 49 & 44 & 61 & 54.4 & 4.4 & 46 & 49 & 60.5 & 55.3 & 3 & .243 & -0.9 & -2.5 & 0.6 \\
\hline MePMe & 49 & 53 & 75 & 66.2 & 5.3 & 46 & 61 & 76 & 66.8 & 4.3 & .548 & -0.6 & -2.6 & 1.4 \\
\hline
\end{tabular}

${ }^{1}$ Independent samples T test. SD=Standard deviation, MD=Mean difference, $\mathrm{Cl}=$ Confidence Interval of the difference ${ }^{* * *}: \mathrm{P}<.001 ;{ }^{* *}: \mathrm{P}<.01 ;{ }^{*}: \mathrm{P}<.05$. 
Table 6. Comparison craniofacial angular values of boys with and without fluorosis by Björk values.

\begin{tabular}{|c|c|c|c|c|c|c|c|c|}
\hline \multirow[t]{2}{*}{ Angular measurements } & \multicolumn{2}{|c|}{$\begin{array}{l}\text { Björk values } \\
\text { N:322 }\end{array}$} & \multicolumn{2}{|c|}{$\begin{array}{l}\text { With fluorosis } \\
\qquad \mathrm{N}: 49\end{array}$} & \multicolumn{4}{|c|}{$\begin{array}{l}\text { Without fluorosis } \\
\qquad N: 46\end{array}$} \\
\hline & Mean & SD & Mean & SD & P1 & Mean & SD & P1 \\
\hline NSAr & 122.9 & 4.9 & 123.1 & 5.3 & .769 & 124.8 & 5.1 & $.017^{*}$ \\
\hline SArGo & 143 & 6.2 & 145.8 & 5.3 & $.001^{* *}$ & 141.5 & 6.9 & .154 \\
\hline ArGoGn & 131.1 & 6.1 & 129.7 & 5.5 & .073 & 132.3 & 6.9 & .25 \\
\hline ArNPr & 65.5 & 3.2 & 63.5 & 3.6 & $.000 * * *$ & 63.4 & 3 & $.000 * * *$ \\
\hline SNPr & 83.7 & 3.7 & 82.3 & 4.1 & $.018^{*}$ & 81.2 & 4 & $.000^{* * *}$ \\
\hline SNId & 78.9 & 3.6 & 78.9 & 4.2 & .957 & 77.6 & 3.5 & $.019^{*}$ \\
\hline IdPog-MGo & 68.6 & 5.4 & 70.9 & 6.1 & $.012^{*}$ & 66.8 & 4.9 & $.016^{*}$ \\
\hline NAPog & 173.9 & 5.6 & 175.3 & 7.8 & .224 & 179.7 & 6.4 & $.000^{* * *}$ \\
\hline
\end{tabular}

${ }^{1}$ One sample $\mathrm{T}$ test. $\mathrm{SD}=$ Standard deviation, $\mathrm{MD}=$ Mean difference, $\mathrm{Cl}=$ Confidence Interval of the difference ***:P<.001; **:P<.01; *:P<.05.

Table 7. Björk Analysis correlations of angular measurements of individuals in general, boys, girls with dental fluorosis.

\begin{tabular}{|c|c|c|c|c|c|c|c|c|c|}
\hline & $\begin{array}{c}\text { Angular } \\
\text { measurements }\end{array}$ & NSAr & SArGo & ArGoGn & ArNPr & SNPr & SNId & IdPog-MGo & NAPog \\
\hline Total & NSAr & & & & & & & & \\
\hline Girls & & & & & & & & & \\
\hline Boys & & & & & & & & & \\
\hline Total & SArGo & $-.642(* * *)$ & & & & & & & \\
\hline Girls & & $-.646(* * *)$ & & & & & & & \\
\hline Boys & & $-.609(* * *)$ & & & & & & & \\
\hline Total & ArGoGn & & $-.224\left(^{*}\right)$ & & & & & & \\
\hline Girls & & & $-.373\left(^{* *}\right)$ & & & & & & \\
\hline Boys & & & & & & & & & \\
\hline Total & ArNPr & & $-.220(*)$ & & & & & & \\
\hline Girls & & & $-.280(*)$ & & & & & & \\
\hline Boys & & & & & & & & & \\
\hline Total & SNPr & $-.408(* * *)$ & & -.189 (*) $^{*}$ & $.733(* * *)$ & & & & \\
\hline Girls & & $-.327(* *)$ & & & $.714(* * *)$ & & & & \\
\hline Boys & & $-.558(* * *)$ & & & $.801(* * *)$ & & & & \\
\hline Total & SNId & $-.437(* * *)$ & & & $.340(* * *)$ & $.656\left[^{* * *}\right)$ & & & \\
\hline Girls & & $-.369\left(^{* *}\right)$ & & & $.346\left(^{* * 1}\right.$ & $\left..6691^{* * *}\right)$ & & & \\
\hline Boys & & $-.566(* * *)$ & & & $\left..3441^{*}\right)$ & $.631(* * *)$ & & & \\
\hline Total & IdPog-MGo & & & $-.294(* *)$ & $.415\left(^{* * *}\right)$ & $.330(* * *)$ & & & \\
\hline Girls & & & & -.249 (*) $^{*}$ & $.393(* * *)$ & $.303(* *)$ & & & \\
\hline Boys & & & & $-.404(* *)$ & $.477\left(^{* *}\right)$ & $.383\left(^{* *}\right)$ & & & \\
\hline Total & NAPog & & $-.217(*)$ & & $-.379(* * *)$ & $-.271(* *)$ & $\left..210{ }^{*}\right]$ & $-.602\left(^{(* * *)}\right.$ & \\
\hline Girls & & & & & $-.324(* *)$ & & & $-.544(* * *)$ & \\
\hline Boys & & & & & $\left.-\left..495\right|^{* * *}\right)$ & $-.400(* * *)$ & & $-.705\left(^{* * *}\right)$ & \\
\hline
\end{tabular}

${ }^{* * *}: \mathrm{P}<.001 ;{ }^{* *}: \mathrm{P}<.01 ;{ }^{*}: \mathrm{P}<.05$ 
or vertical boundaries on the cephalogram, would have a pronounced effect on the alveolar section. How great the effect on the angle of prognathism will be, depends upon whether the change in the chin angle is accompanied by a corresponding change in the upper jaw. Chin angle showed positive correlation with facial prognatism and maxillary prognathism as in Björk's. ${ }^{10}$ The reason may be the posterior growth of condyles and the resorption in the anterior bone surface of mandibular incisors as mentioned in Björk and Skiller's study. ${ }^{25}$

Mandibular prognathism increases by the increment of facial and maxillary prognatism as Björk mentioned in his thesis. Nevertheless, NAPog decreases with all this incremental values of prognathy angles. This can be the result of posterior rotation of mandible. Schudy ${ }^{26}$ and Björk ${ }^{10}$ explained this situation like this: the growth of corpus antero-posteriorly more than expected yield to the inclination of gonial angle downwards so as the large mandible can be placed. This is accepted as naturally compensation mechanism so as the anatomical complex can be harmonized. As the mandible grows antero-posteriorly, gonial angle found to be greater. But in our study, gonial angle did not increase with the increment of facial and maxillary prognathy which might be the result of posterior growth of condyle as in the second theory of Björk's growth development. The increment of IdPog-MGo is the other important compensation mechanism for the decrement of NAPog by the increment of prognathy angles. Increment of chin angle yields to mandibular prognatism and maxillary and facial prognatism.

Although studies relating fluoride to bone have been rather inconclusive, it has been stated that 'sodium fluoride has clearly been shown to have pronounced effects on the skeleton'. ${ }^{27}$ For this reason, studies of this type continue to be important especially on facial growth and development studies. ${ }^{28}$

\section{CONCLUSIONS}

- Craniofacial morphology of children with fluorosis did not show great diversity than the ones without fluorosis in the early permanent dentition period.

- None of the angular measurements were significantly different between boys and girls in the fluoridated group which might imply that systemic fluorosis did not show gender difference in the early permanent dentition.

\section{REFERENCES}

1. Ishii T, Suckling G. The severity of dental fluorosis in children exposed to water with a high fluoride content for various periods of time. J Dental Res 1991;70:952-956.

2. Savas S, Cetin M. Akdogan M. Heybeli N. Endemic fluorosis in Turkish patients: relationship with knee osteoarthritis. Rheumatol Int 2001;21:30-35.

3. Ermis RB, Koray F, Akdeniz BG. Dental caries and fluorosis in low- and high-fluoride areas in Turkey. Quintessence Int 2003;34:354-360.

4. Pendrys DG. Fluoride ingestion and oral health. Nutrition 2001;17:979-980.

5. Kierdorf H, Kierdorf U, Sedlacek F, Erdelen M. Mandibular bone fluoride levels and occurrence of fluoride induced dental lesions in populations of wild red deer (Cervus elaphus) from Central Europe. Environ Pollut 1996;93:75-81.

6. Kierdorf U, Kierdorf H, Sedlacek F, Fejerskov O. Structural changes in fluorosed dental enamel of red deer (Cervus elaphus L.) from a region with severe environmental pollution by fluorides. J Anat 1996;188:183-195

7. Xu JC, Wang YZ, Xue DM, Xin SZ, Dai RT, Zhang ZL, Cheng $X$. X-ray findings and pathological basis of bone fluorosis. Chin Med J (Engl) 1987;100:8-16.

8. Czarnowski W, Krechniak J, Urbanska B, Stolarska K. Traszewska-Czarnowska M. Muraszko-Klaudel A. The impact of water-borne fluoride on bone density. Fluoride 1999;32:91-95.

9. Vieira AP, Mousny M, Maia R, Hancock R, Everett ET, Grynpas MD. Assessment of teeth as biomarkers for skeletal fluoride exposure. Osteoporos Int 2005;16:1576-1582.

10. Björk A. The face in profile. Svensk Tandlaekare-Tidskrift. Vol. 40; No. 5B. suppl. Berlingska. Boktrykeriet. Lund. 1947

11. Thylstrup A, Fejerskov 0. Clinical appearance of dental fluorosis in permanent teeth in relation to histological changes. Community Dent Oral Epidemiol 1978;6:315-328.

12. Dahlberg G. Statistical methods for medical and biological students. New York: Interscience Publications, 1940.

13. Standing Committee on the Scientific Evaluation of Dietary Reference Intakes. Food and Nutrition board. Institute of Medicine. Dietary reference intakes for calcium. phosphorus. magnesium. vitamin D and fluoride. Washington. DC: National Academy Pres; 1997.

14. Kierdorf U, Kierdorf H. Dental fluorosis in wild deer: its use as a biomarker of increased fluoride exposure. Environ Monit Assess 1999;57:265-275. 
15. Chavassieux P, Pastoureau P, Boivin G, Chapuy MC, Delmas PD, Milhaud G, Meunier PJ. Fluoride-induced bone changes in lambs during and after exposure to sodium fluoride. Osteoporos Int 1991;2:26-33.

16. Sogaard CH, Mosekilde L, Schwartz W, Leidig G, Mine HW, Ziegler R. Effects of fluoride on rat vertebral body biomechanical competence and bone mass. Bone 1995;16:163169.

17. Sogaard CH, Mosekilde L, Richards A, Mosekilde L. Marked decrease in trabecular bone quality after five years of sodium fluoride therapy assessed by biomechanical testing of iliac crest bone biopsies in osteoporotic patients. Bone 1994;15:393-399.

18. Lundy MW, Stauffer M, Wergedal JE, Baylink DJ, Featherstone JD, Hodgson SF, Riggs BL. Histomorphometric analysis of iliac crest bone biopsies in placebo-treated versus fluoride-treated subjects. Osteoporos Int 1995;5:115-129.

19. Turner CH, Hasegawa K, Zhang W, Wilson M. Li Y, Dunipace AJ. Fluoride reduces bone strength in older rats. J Dent Res 1995; 74:1475-1481.

20. Miyagi M, Tsuruda K, Kawamura M, Morishita M, Iwamoto Y. Effects of fluoride intake on the mineral content . acid solubility and resorption caused by experimental periodontitis of rat alveolar bone. Arch Oral Biol 1994;39:163-166.

21. Grynpas MD. Fluoride effects on bone crystals. J Bone Miner Res 1990;5 Suppl 1: S169-175.

22. El-Batouti A, Ogaard B, Bishara S. Longitudinal cephalometric standards for Norwegians between the ages of 6 and 18 years. Eur J Orthod 1994;16:501-509.

23. Johannsdottir B, Thordarson A, Magnusson TE. Craniofacial morphology in 6 year old Icelandic children. Eur J Orthod 1999;21:283-290.

24. Jarvinen S. Saddle angle and maxillary prognathism: a radiological analysis of the association between the NSAr and SNA angles. Br J Orthod 1984;11:209-213.

25. Björk A, Skieller V. Normal and abnormal growth of the mandible. A synthesis of longitudinal cephalometric implant studies over a period of 25 years. Eur $J$ Orthod 1983;5:1-46.

26. Schudy F. Superimposition and structural analysis. Am J Orthod Dentofacial Orthop 1996;109:193-195.

27. Kleerekoper M, Balena R. Fluorides and osteoporosis. Annu Rev Nutr 1991;11:309-24.

28. Warren JJ, Levy SM. Systemic fluoride sources, amounts and effects of ingestion. Dent Clin North Am 1999;43;695711. 